\title{
Microstructure and Tensile Strength of Stainless Steel Wires Micro Spot Melted by YAG Laser
}

\author{
Keisuke Uenishi ${ }^{1}$, Masanori Seki ${ }^{1, * 1}$, Masaya Takatsugu ${ }^{1, * 2}$, Takeshi Kunimasa ${ }^{1, * 3}$, \\ Kojiro F. Kobayashi ${ }^{1}$, Takeshi Ikeda ${ }^{2}$ and Akihiko Tsuboi ${ }^{2}$ \\ ${ }^{1}$ Department of Manufacturing Science, Graduate School of Engineering, Osaka University, Suita 565-0871, Japan \\ ${ }^{2}$ Fine Process Co. Ltd., Electronic Materials Division, Nagoya 457-0823, Japan
}

SUS304 stainless steel wire was micro spot melted by using YAG laser to investigate the applicabilty to the fabrication of biomedical devices. Effects of laser conditions such as laser power input or pulse duration were investigated on the microstructure and tensile strength of spot melted wires. Width of the melted metal decreased by laser irradiation with a shorter pulse duration and was about $0.3 \mathrm{~mm}$ for the $0.35 \mathrm{~mm}$ diameter wires. On the contrary, laser spot melting with a shorter pulse duration needed more precise control of laser conditions to achieve the sound melting free from burn out of the samples. Similarly, melting of thinner wire needed more precise control of laser conditions. Melted metal exhibited a rapidly quenched austenite cell microstructure with a cell size of less than about $5 \mu \mathrm{m}$. Tensile strength of the spot melted wires was $660 \mathrm{MPa}$, which was almost the same as that of annealed base materials. Besides, corrosion resistance in a quasi biological environment was hardly degraded by spot melting. Crosswise joints was also successfully prepared by laser spot welding of wires, suggesting the laser micro welding is applicable to the fabrication of biomedical devices.

(Received June 21, 2002; Accepted September 20, 2002)

Keywords: micro laser welding, spot melting, crosswise joint, rapid solidification, Nd:YAG laser, stainless steel, biomaterials, joint strength, corrosion resistance

\section{Introduction}

Stainless steel was firstly used for the fixation of the fractured bones in the 1920's' 1 ) and is still a major material to produce medical devices due to the superior machinability and corrosion resistance in a biological environment. Development of medical devices such as stent, catheter or coil anchor implanted in human body has played a key role in the recent progress on medical treatments. One of the mostly desired demands against these devices is to minimize the size, because smaller devices readily expand their application parts of human body. ${ }^{2)}$ However at this moment, it is not always easy because they are almost the hand made products based on the deformation process. Thus the establishment of the alternative production process is an urgent issue. If welding process is applicable to the production of finer medical devices, it will be a great advantage because it enables the mass production of the devices. Recently, laser micro processing using YAG laser has been reported to be effective and been tried to apply to the production of the electronics packaging and so on. ${ }^{3,4)}$

The objective of this research is to investigate the micro weldability of biomaterials and to discuss the applicability of laser micro welding to the fabrication of medical devices. For the basic investigation of micro weldability, stainless steel wire was spot melted by YAG Laser. By the measurement of mechanical properties of the joints, the effect of laser conditions on the joint reliability was discussed.

Moreover, for the practical application of the medical devices fabricated by laser processing, many corrosion tests in a biological environment are legally obligated, which takes a

\footnotetext{
${ }^{* 1}$ Graduate Student, Present address: Sharp Co. Ltd., Tenri 632-0004, Japan.

${ }^{* 2}$ Graduate Student. Osaka University.

${ }^{* 3}$ Graduate Student, Present address: Kansai Electronic Power Co. Inc., Fukui 919-2362, Japan.
}

long period of time and cost. At an elemental stage to estimate the corrosion resistance, the microstructural observation of laser melted material is considered to be effective. For the stainless steel, there are many researches on the weldability by laser welding, ${ }^{5)}$ arc welding ${ }^{6)}$ and so on. ${ }^{7)}$ On the benefit of the researches, very reliable database about the relation between microstructure and corrosion resistance has already been established. In this work, microstructure of the spot melted or the heat affected material was intensively observed, and then corrosion resistance was estimated from the microstructure. Finally, taking the actual application of laser micro welding into consideration, crosswise welded joints were prepared and their joint reliability was investigated.

\section{Experimental Procedure}

Austenitic stainless steel wire (SUS304) with a diameter of $0.25 \mathrm{~mm}$ or $0.35 \mathrm{~mm}$ was used in this study. These wires were spot melted by a single pulsed and just focused laser irradiation using a Nd-YAG laser equipment (Lumonics JK701) in an Ar shielding atmosphere. Frequency, focal distance and theoretically estimated radius of the laser beam were $20 \mathrm{~Hz}$, $80 \mathrm{~mm}$, and $400 \mu \mathrm{m}$, respectively. As the parameters of laser spot melting, power input and pulse duration were varied from 0.5 to $10.0 \mathrm{~J}$ and from 1 to $10 \mathrm{~ms}$, respectively.

Microstructural observation of the spot melted and heat affected area was performed by using optical microscope and scanning electron microscope (SEM) after electro chemical etching of the polished samples by $10 \%$ of oxalic acid. In order to investigate the effect of laser conditions on the morphology of laser melted region, peneration depth and width of spot melted metal defined in Fig. 1, were measured for the each specimen. For the tensile test, as spot melted materials with a gage length of $100 \mathrm{~mm}$ and a grab length of $150 \mathrm{~mm}$ 
were strained at a cross-head speed of $3.3 \times 10^{-3} \mathrm{~mm} / \mathrm{s}$. To estimate the corrosion resistance in a quasi biological environment, microstructure and tensile strength of the samples after the immersion in a $0.9 \% \mathrm{NaCl}$ (JIS T0302) at $318 \mathrm{~K}$ for $1800 \mathrm{ks}$ and $3600 \mathrm{ks}$ were compared with those of as spot melted or as received stainless steel wires.

Crosswise welding was also performed by using the $0.35 \mathrm{~mm}$ diameter wires with the same laser conditions as those for spot melting. Similar to the case of laser spot melting, effect of laser power input on the joint tensile strength was investigated.

\section{Results and Discussion}

\subsection{Spot melting}

\subsubsection{Effect of laser condition on the spot melting}

Figure 2 shows the cross sections of spot melted stainless steel wires. Any cracks or porosities were not confirmed, but especially in a shorter pulse duration, the morphology of the sample became irregular probably due to the increased power density of laser. With increasing the power input, the penetration depth and melted area increased, but too much power input caused the break down of the wires after melting.

Figure 3 shows the effect of power input on penetration ratio, which is the ratio of penetration depth to the wire diameter, and on the width of spot melted metal. With decreasing the pulse duration and wire diameter, width of melted metal decreased. By using a shorter pulse duration of laser, the sound melting with the weld meld width of less than

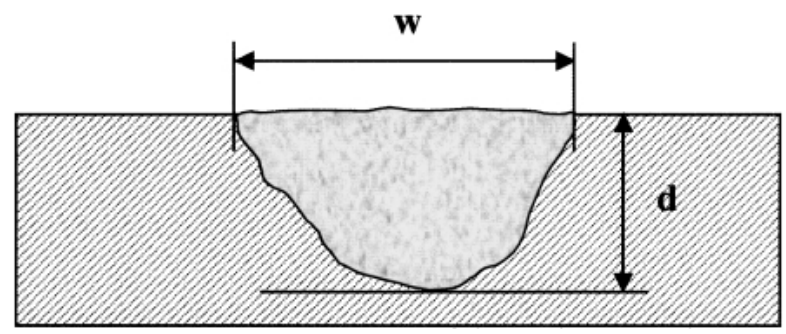

Fig. 1 Definition of melted metal width $(w)$ and penetration depth $(d)$ in cross section.

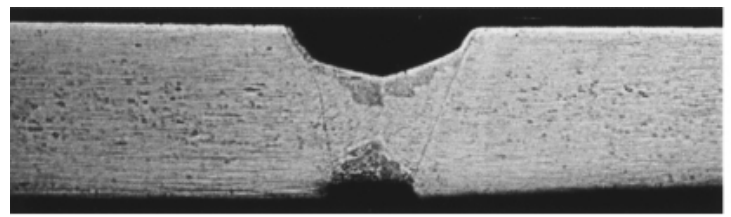

(a) $1 \mathrm{~ms} 0.7 \mathrm{~J}$

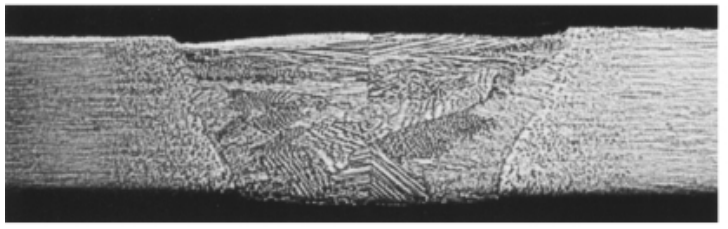

(c) $5 \mathrm{~ms} 3.0 \mathrm{~J}$
$0.3 \mathrm{~mm}$ was achieved for the $0.35 \mathrm{~mm}$ diameter wires. On the contrary, the favorable laser condition range where fully penetrated melting without any melting imperfections can be achieved, became smaller for the shorter pulse duration and also for the thinner wires as shown in Fig. 4. It can be concluded that laser spot melting with a shorter pulse duration is effective to minimize the melted area because of the smaller laser power input, but needs more precise control of laser conditions to achieve the stable melting. Similarly, melting of thinner wire needs more precise control of laser conditions.

\subsection{Microstructure of spot melted metal}

Figure 5 shows the representative microstructure of spot melted and heat affected materials by laser. In entire laser conditions, the microstructure of the melted metal was a austenite cellular dendrite structure that grew from fusion boundary to center of the melted metal. $\delta$ ferrite, which is contrasted as dark holes, was slightly observed on the boundary of primary precipitated austenite cell ${ }^{8,9)}$ especially around the center of the melted metal. The cell size changed by the position, and it was about $2.5-3.5 \mu \mathrm{m}$ near the center and was $0.5-1.5 \mu \mathrm{m}$ for fusion boundary, which became slightly larger with increasing the power input. Such a fine cell microstructure has been observed for the rapidly quenched stainless steels like laser surface melting. By referring previously estimated the relation between cell size and cooling rate, ${ }^{10}$ ) the cooling rate during laser melting was estimated about $2 \times 10^{5}-2 \times 10^{6} \mathrm{~K} / \mathrm{s}$ around fusion boundary and about $5 \times 10^{3}-$ $3 \times 10^{4} \mathrm{~K} / \mathrm{s}$ around center of the melted metal.

Stainless steel with a fine grained structure and smaller volume fraction of $\delta$ ferrite is reported to rather enhance the corrosion resistance, ${ }^{11,12)}$ so at least it can be presumed that laser spot melting will not degrade the corrosion resistance of SUS304.

The microstructure of heat affected material, shown in Fig. $5(d)$, was a recrystallized or a fiber structure, since the base material is highly deformed for drawing. This microstructure was also observed by tempering the base metal at $1173 \mathrm{~K}$. For the arc or laser welded stainless steel, sensitization in heat affected zone (HAZ) frequently degrades the corrosion resistance. It has been reported that HAZ after etching by oxalic

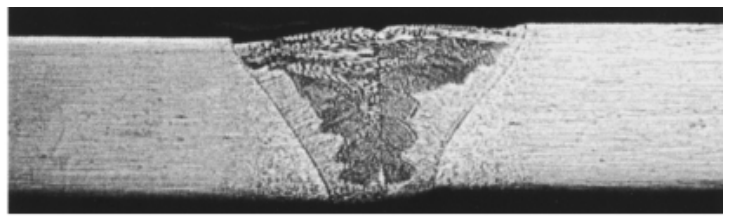

(b) $2 \mathrm{~ms} 1.2 \mathrm{~J}$

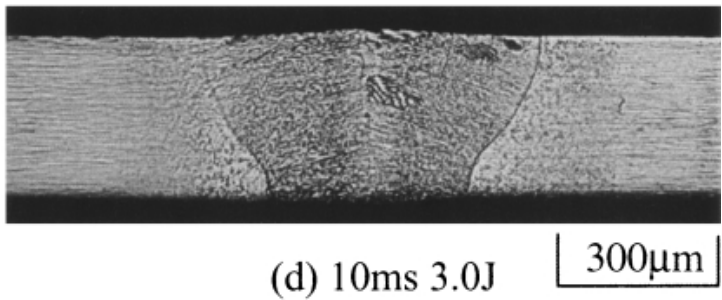

Fig. 2 Cross sections of stainless steel wires spot melted by various power input and pulse duration. 

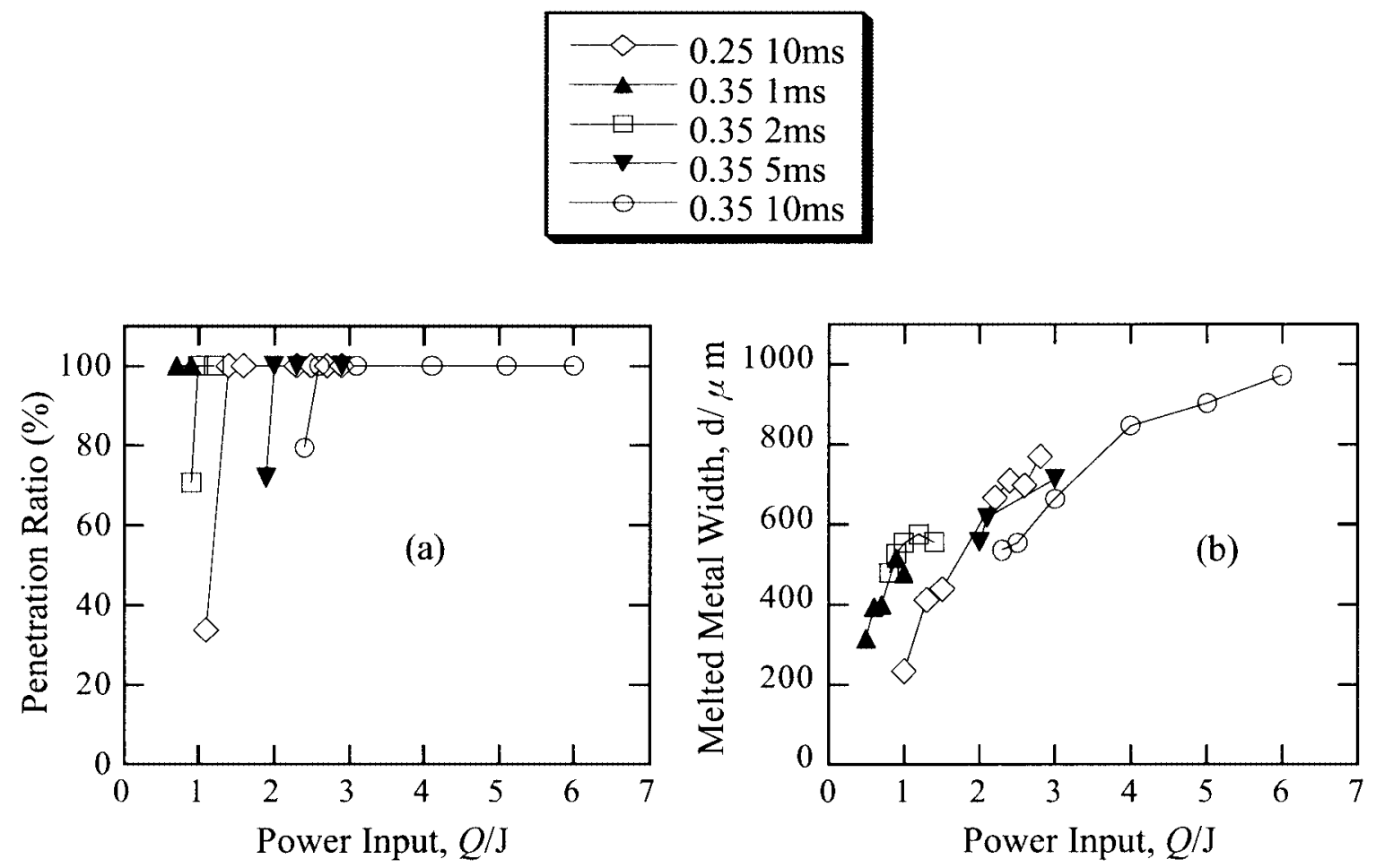

Fig. 3 Effect of power input on (a) penetration ratio and (b) width of the spot melted metal.

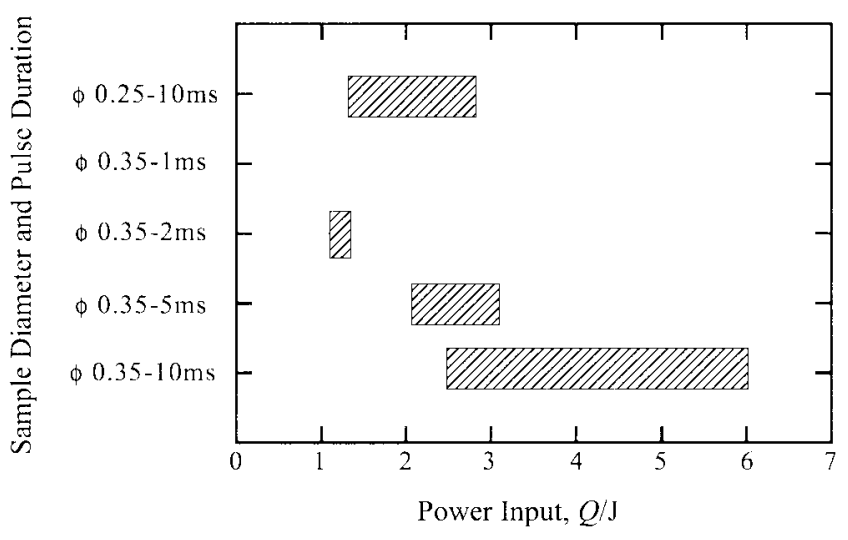

Fig. 4 Laser condition range where reasonable melting can be achieved.

acid exhibits a ditch like microstructure when sensitization of HAZ occurs. ${ }^{13)}$ For the samples obtained in this research, HAZ exhibited not a ditch structure but a step-like structure similar to that of the tempered base metal. Consequently, corrosion of HAZ can be considered to be comparable with base materials.

\subsection{Properties of spot melted stainless steel}

Figure 6 shows the effect of laser conditions on the tensile strength of spot melted stainless steel. In any welding conditions, tensile strength slightly increased with decreasing the input energy and reached to a maximum about $660 \mathrm{MPa}$ both for the $\phi 0.25$ and $\phi 0.35$ wires. Fracture occurred in the melted metal and fracture surface revealed a ductile cup-andcone structure.

Compared with the tensile strength of the base metal, which was about $2300 \mathrm{MPa}$, that of spot melted material was smaller since base metal is rather strengthened by work hardening. Although the fracture elongation hardly changed between base metals and spot melted wires, the reduction in the area was much larger for spot melted wires than that for base metals. So it can be concluded that melted metal is more ductile than base metal. When base metal is tempered at $1173 \mathrm{~K}$, the tensile strength decreased down to about $600 \mathrm{MPa}$, which is comparable with that of the spot melted material obtained in this study.

Figure 7 shows the changes in the tensile strength of spot melted wires by the immersion in a pseudo biological environment using a $\mathrm{NaCl}$ solution.

By the immersion for $1000 \mathrm{~h}$, the melted area hardly attacked and tensile strength did not changed. So the laser melted material is presumed to retain favorable corrosion resistance in a biological environment.

\subsection{Crosswise welding of stainless steel wires}

Figure 8 shows the general view and cross section of crosswise welded joints. Welding free from welding imperfections like crack and porosity was achieved. When welding was performed by various laser conditions, weld joints morphologies were classified into 3 types by the melting state of a lower wire. Namely, lower wire is hardly melted, partially melted and fully melted. When input energy was less than $4.0 \mathrm{~J}$, lower wire was hardly melted. Melted area of lower wire increased with increasing input energy. The joint exhibited the maximum tensile fracture load of $80 \mathrm{~N}$ which is slightly higer than that for spot melted wires when lower wire was partially melted and fracture occurred in the boundary between weld metal and HAZ.

The microstructure of the weld metal was a cellular dendrite structure similar to that of spot melted metal. Cell size 


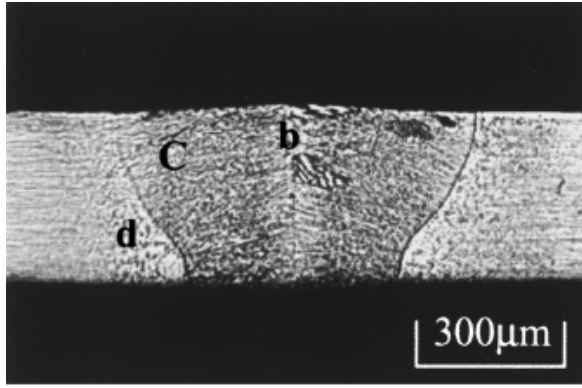

(a) General view

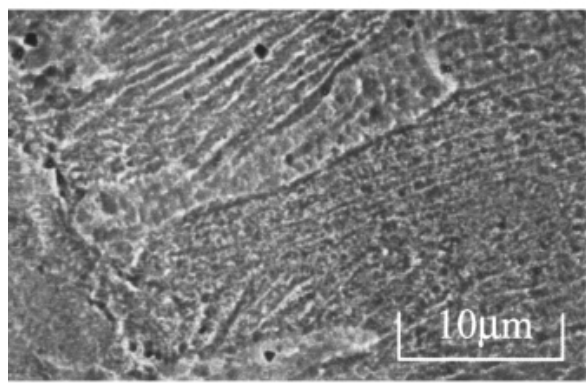

(c) Fusion boundary

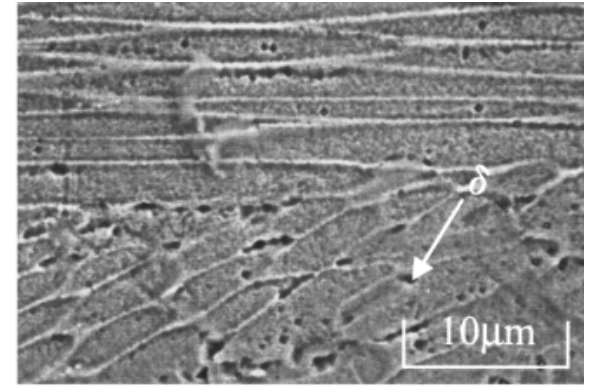

(b) Center

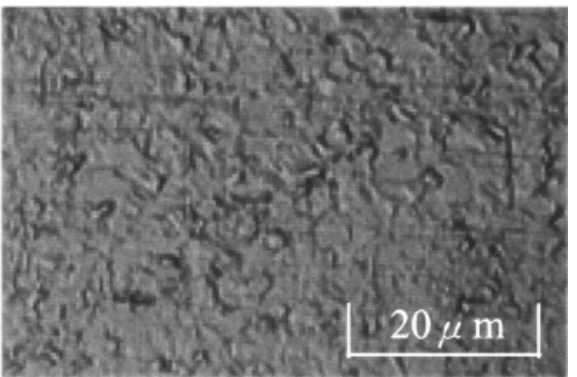

(d) Heat affected

Fig. 5 Microstructure of spot melted and heat affected SUS304 prepared by the 3.0J of power input and $10 \mathrm{~ms}$ of pulse duration.

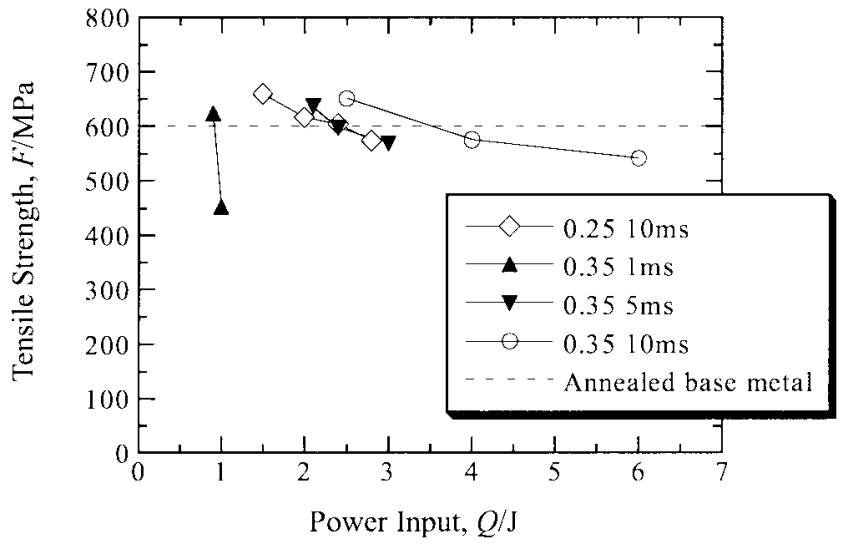

Fig. 6 Effect of laser conditions on the tensile strength of spot melted stainless steel.

was about $1.0 \mu \mathrm{m}$ around fusion boundary and about $5.0 \mu \mathrm{m}$ around center of the weld metal. By referring the relation between cell size and cooling rate, the cooling rate during laser welding was estimated about $4 \times 10^{5} \mathrm{~K} / \mathrm{s}$ around fusion boundary and about $1 \times 10^{3} \mathrm{~K} / \mathrm{s}$ around center of the weld metal. Although cell size of crosswise welded metal was a little larger than that of spot melted metal, it is considered that this will hardly affect the corrosion resistance.

\section{Conclusions}

SUS304 stainless steel wires were micro spot melted by using YAG laser in order to investigate the applicability of laser micro welding to the fabrication of medical devices. The

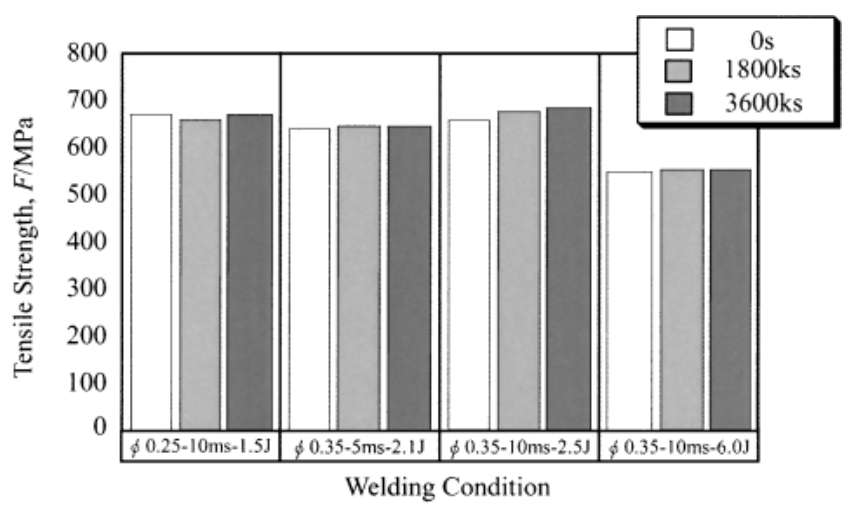

Fig. 7 Effect of immersion time in $0.9 \% \mathrm{NaCl}$ at $328 \mathrm{k}$ on tensile strength of spot melted wires.

results are summarized as follows.

(1) Both for the $0.25 \mathrm{~mm}$ and $0.35 \mathrm{~mm}$ diameter wires, sound spot melted samples free from any defects were prepared. With increasing the power input, the penetration depth and melted area increased, but too much power input caused the break down of the wires after melting. Laser irradiation with a shorter pulse duration is effective to minimize the melted area but needs more precise control of laser conditions to achieve the stable melting. Similarly, melting of thinner wire needs more precise control of laser conditions. Melted metal width decreased with decreasing the input energy and pulse duration.

(2) The microstructure of the melted metal was a austenite cellular dendrite structure with a cell size of less than about 


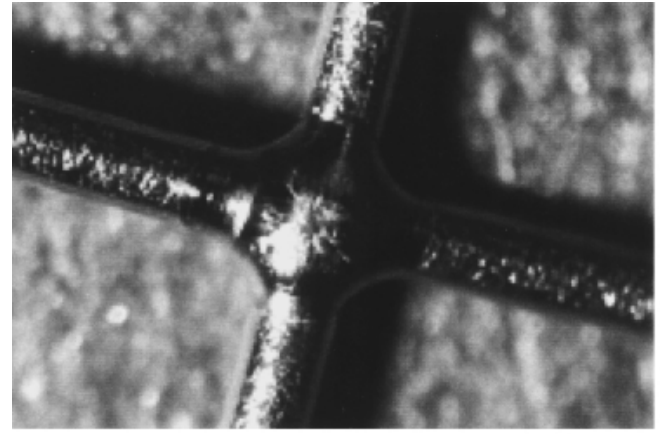

(a) General view

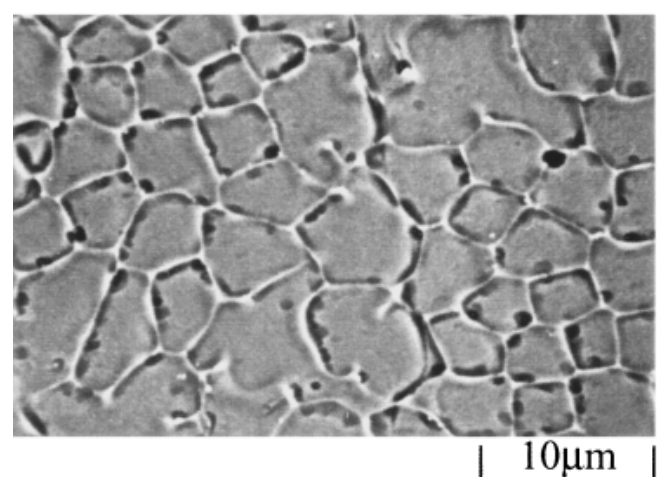

(c) Center of weld metal

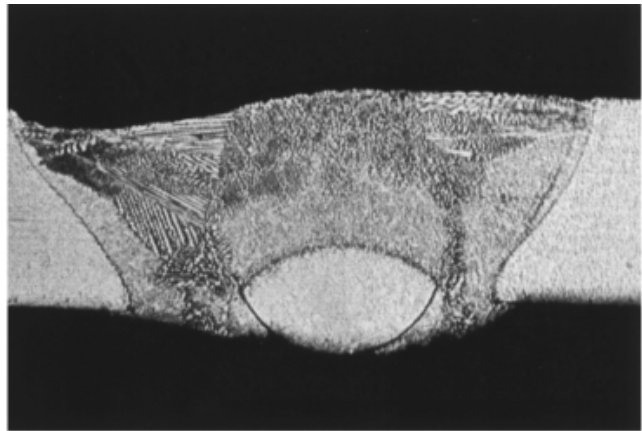

(b) Cross section

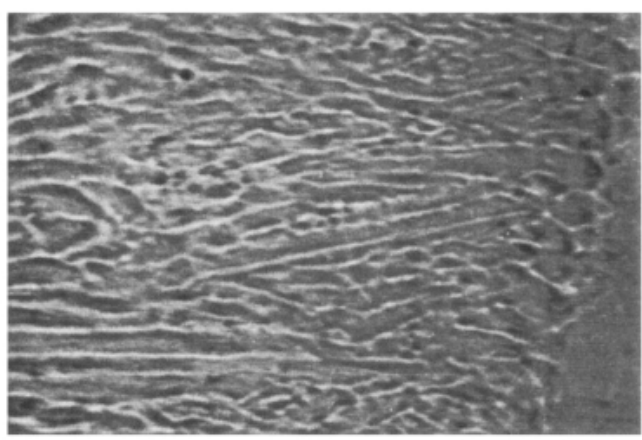

(d) Fusion boundary

Fig. 8 General view and cross section of crosswise weld joints prepared by the $6.0 \mathrm{~J}$ of power input and $10 \mathrm{~ms}$ of pulse duration.

$5 \mu \mathrm{m} . \delta$ ferrite was slightly observed on the boundary of primary precipitated austenite cell especially in the center of the melted metal. This microstructure was developed by the rapid solidification of melted materials at a approximate order of $10^{4} \mathrm{~K} \mathrm{~s}^{-1}$. The microstructure of HAZ was a recrystallized microstructure. Any sensitizations in HAZ were not recognized.

(3) Tensile strength of the spot melted wires was $660 \mathrm{MPa}$, which is almost the same as that of tempered base materials.

(4) By the immersion in a quasi biological environment, microstructure and tensile strength of the spot melted wires hardly changed from those for as melted wires. Coupled with the results of the microstructural observation for the spot melted and heat affected material, corrosion resistance of the melted samples is estimated to be comparable with that of base material.

(5) Crosswise joints were also successfully prepared by laser spot welding of wires. The maximum tensile fracture load reached to $80 \mathrm{~N}$, suggesting the laser micro welding is applicable to the fabrication of biomedical devices.

\section{Acknowledgements}

The authors thank the staffs in Laserx Co. Ltd., for the ex- perimental help about laser irradiation. This research is financially supported by JSPS grant-in aid for Scientific Research.

\section{REFERENCES}

1) H. Hamanaka: Materia Japan 37 (1998) 834-841 (Japanese).

2) T. Yoneyama and I. Kobayashi: Nondesructive inspection 49 (2000) 420-423 (Japanese).

3) W. S. Chang and S. J. Na: J. Mater. Proc. Tech. 120 (2002) 208-214.

4) K. Uenishi, M. Seki, M. Takatsugu, K. F. Kobayashi, T. Ikeda and A. Tsuboi: Proc. Inter. Cong. on Laser Advanced Materials Processings, (2002) Osaka Japan, in press.

5) K. Nishimoto: J. Jpn. Weld. Soc. 66 (1997) 24-41 (Japanese).

6) Y. Araki and F. Matsuda: J. High Temper. Soc. 1 (1975) 160-168 (Japanese).

7) M. Seki, H. Yamamoto, M. Nojiri, K. Uenishi and K. F. Kobayashi: J. Japan Inst. Metals. 64 (2000) 632-640 (Japanese).

8) K. Nishimoto, H. Mori and Y. Nakao: ISIJ Int. 35 (1995) 1265-1271.

9) K. Nishimoto, H. Mori and Y. Nakao: IIW Doc. IX-1783-94 (1995) $1-15$.

10) W. P. Zhang: Doctoral thesis, Osaka University, September (1989).

11) Y. Nakao, K. Nishimoto and M. Ishizaki: Quart. J. Jpn. Weld Soc. 9 (1991) 97-104.

12) Y. Nakao, K. Nishimoto and W. P. Zhang: Quart. J. Jpn. Weld Soc. 9 (1991) 111-116.

13) H. Kokawa: Materia Japan 35 (1996) 655-662 (Japanese). 